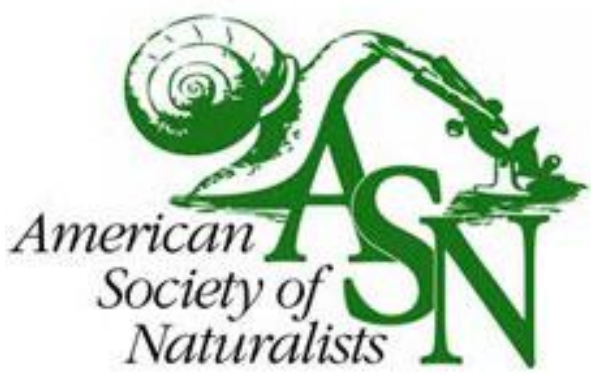

Shared Preferences by Predators and Females for Male Ornaments in Swordtails Author(s): Gil G. Rosenthal, Tania Y. Flores Martinez, Francisco J. García de León and Michael J. Ryan

Source: The American Naturalist, Vol. 158, No. 2 (August 2001), pp. 146-154

Published by: University of Chicago Press for American Society of Naturalists

Stable URL: http://www.jstor.org/stable/10.1086/321309

Accessed: 28-02-2016 00:43 UTC

Your use of the JSTOR archive indicates your acceptance of the Terms \& Conditions of Use, available at http://www.jstor.org/page/ info/about/policies/terms.jsp

JSTOR is a not-for-profit service that helps scholars, researchers, and students discover, use, and build upon a wide range of content in a trusted digital archive. We use information technology and tools to increase productivity and facilitate new forms of scholarship. For more information about JSTOR, please contact support@jstor.org. 
VOL. 158, NO. 2 THE AMERICAN NATURALIST AUgUST 2001

\title{
Shared Preferences by Predators and Females for Male Ornaments in Swordtails
}

\author{
Gil G. Rosenthal, ${ }^{1, *}$ Tania Y. Flores Martinez, ${ }^{2, \dagger}$ Francisco J. García de León, ${ }^{2, \star}$ and Michael J. Ryan ${ }^{1, \S}$
}

1. Section of Integrative Biology C0930, College of Natural Sciences, University of Texas, Austin, Texas 78712;

2. Laboratorio de Biología Integrativa, Instituto Tecnológico de Ciudad Victoria, Ciudad Victoria, Tamaulipas 87010, Mexico

Submitted September 27, 2000; Accepted March 27, 2001

ABSTRACT: Sexually dimorphic traits in many mate recognition systems have evolved in response to preexisting female biases. These biases are often quite general in form and are likely to be shared by predators, thereby imposing a cost on male trait expression. The Mexican tetra Astyanax mexicanus (Pisces: Characidae), a visual predator of swordtail fishes, exhibits the same visual preferences for male body size morphs as do females. Furthermore, tetras in populations where swordtails are absent prefer males with sword ornaments over males with swords removed. The predator preference is thus likely to have arisen prior to contact with fishes bearing the ornament, as has also been suggested for mating preferences for swords.

Keywords: sexual selection, visual signals, predation, Poeciliidae, Xiphophorus.

Sexual selection often favors conspicuous traits, an advantage counterbalanced by the fact that predators are often preferentially attracted to sexual ornaments (Endler 1980, 1983; reviewed in Zuk and Kolluru 1998). Such attraction can arise in at least two ways. Predator sensitivity can coevolve with the display trait, a phenomenon particularly well documented with acoustic cues (e.g., Tuttle and Ryan 1981; Wagner 1996).

Conspicuousness to receivers, however, need not arise through a coevolutionary process (Basolo 1990b; Endler 1992; Burley and Symanski 1998; Ryan 1998). Biases to-

\footnotetext{
* Present address: Department of Biology 0116, University of California, San Diego, La Jolla, California 92093; e-mail: fishman@biomail.ucsd.edu.

† E-mail: tayissel@hotmail.com.

${ }^{\ddagger}$ E-mail: garciadl@prodigy.net.mx.

`E-mail: mryan@mail.utexas.edu.
}

Am. Nat. 2001. Vol. 158, pp. 146-154. (C) 2001 by The University of Chicago. 0003-0147/2001/15802-0004\$03.00. All rights reserved. ward particular cues may arise from selection in another context (e.g., Proctor 1991) or emerge from other perceptual tasks (Enquist and Arak 1993). There are numerous instances of such preexisting preferences in the context of mating (Ryan 1998). In such cases, conspicuous male traits have evolved in response to latent biases in females.

Preexisting preferences can also manifest themselves in predators, although this has rarely been demonstrated. Sparrowhawks are more likely to prey on great tits artificially supplied with bright red markings, even though these ornaments are not normally present in the species (Götmark and Olsson 1997). For visual traits, it is particularly likely that any preexisting female biases will be shared with predators. An increase in conspicuousness almost always involves an increase in brightness, size, or contrast with the background (Ryan and Keddy-Hector 1992; Andersson 1994). Visual predators of displaying animals are particularly likely to share many features of visual perception with their prey. Similar environmental light conditions will select for similar perceptual traits. If predators are to detect unornamented individuals of the prey species, these must be within the range of their spatial frequency sensitivity and detectable, at least to some degree, from the background. These attributes make it likely that any trait that is conspicuous to potential mates will also be conspicuous to predators. While conspicuous visual traits are likely to carry increased predation risk, there are only a handful of studies where this has been demonstrated (Zuk and Kolluru 1998; see Moodie 1972; Haas 1976; Endler 1978, 1983; Slagsvold et al. 1995). Few, if any, of these can differentiate between preexisting bias and a coevolutionary scenario where predator perception of prey has evolved in response to prey signals.

This study focuses on two related traits in male swordtails (Poeciliidae: Xiphophorus). Males have evolved swords-colored elongations of the caudal fin with contrasting components-in response to a preexisting preference on the part of females (Basolo 1990b, 1995b). Preferences for swords are found in swordless platyfish (Basolo 1990b) and Priapella olmecae (Basolo 1995b), which diverged from swordtails prior to the origin of the sword. 
This preference appears to reflect a more general bias for large apparent size: the preference of female Xiphophorus helleri for swords is abolished when the size of a swordless male is augmented to match that of a male with a sword (Rosenthal and Evans 1998).

The preference for body size is broadly shared as well. In the northern swordtails Xiphophorus multilineatus and Xiphophorus nigrensis, most variation in male body size can be explained by variation at the $P$ locus on the $\mathrm{Y}$ chromosome. Small males reach sexual maturity earlier, are slender bodied, and lack conspicuous courtship displays. Large and intermediate males mature later, have robust bodies, and perform elaborate displays to potential mates (Ryan and Causey 1989; Zimmerer and Kallman 1989). Female northern swordtails X. multilineatus, X. nigrensis, and some populations of Xiphophorus pygmaeus all show preferences for large body size classes (Ryan and Wagner 1987; Ryan et al. 1990). Female X. nigrensis show preferences for large and intermediate males over small males but not between large and intermediate males (Ryan et al. 1990). Female preference for body size is likely an ancestral trait as well, widely present in poeciliids and other taxa (Rosenthal and Evans 1998). Both the presence of swords and the length of swords are correlated with genotype: intermediate and large males tend to express longer swords and are more likely to express swords (Rosenthal 2000).

A visual preference for large size is widespread in many ethological contexts (Staddon 1975; Ryan and KeddyHector 1992) and may arise from the fact that large objects stimulate a larger area of the retina (Rowland 1989). Predators are often size selective, preferring larger prey (Wilbur 1988), although there are few studies addressing the basis of this preference. In one case, bluegill sunfish preferred daphnia of larger apparent size (independent of actual size; O'Brien et al. 1976). These factors suggest that visual predators of swordtails may share with their prey an ancient preference for large size, manifesting itself as a bias for both large males and males with swords.

Northern swordtails are restricted to small, shallow streams with a low diversity of diurnally active animals that are potential visual predators. The eleotrid fish Gobiomorus dormitor is present at very low densities in a small subset of northern swordtail populations; gut content analyses reveal that these fishes prey on fishes and aquatic insects (Rosenthal 2000). Cichlid fishes, including Herichthys ("Cichlasoma") labridens and Herichthys carpintes, co-occur with every northern swordtail species. Gut content analyses of $H$. labridens from the Río Choy, where they co-occur with $X$. nigrensis, indicate that fishes are only an occasional prey item, with snails forming the majority of the diet (G. G. Rosenthal, T. Y. F. Martinez, M.
J. Stephens, F. J. G. de Leon, and M. J. Ryan, unpublished data).

The Mexican tetra Astyanax mexicanus co-occurs with every northern swordtail species except Xiphophorus malinche. The natural range of the species extends across the Atlantic slope from the Rio Grande (Río Bravo del Norte) drainage, through the Río Pánuco basin, and south to the Río Cazones and upland Río Papaloapan systems (Miller and Smith 1986). They are sympatric with northern swordtails in the Río Pánuco and nearby internal drainages. The Sierra Tamaulipas, formed during the Eocene, and $>1,000$ $\mathrm{km}$ separate A. mexicanus in the Rio Grande drainage from conspecifics and swordtails in the Río Pánuco drainage.

Astyanax mexicanus is opportunistic and omnivorous, with a broad diet including algae, aquatic insects, benthic invertebrates, and fishes (Birkhead 1980). In swordtail habitat, A. mexicanus form shoals ranging from tens to thousands of individuals (Rosenthal 2000). Fishes comprise approximately $10 \%-15 \%$ of identifiable gut content volume of Mexican tetras in the Río Choy, where they cooccur with $X$. nigrensis. Because A. mexicanus take small bites out of prey items, individual food items in the gut of A. mexicanus were not identifiable to species (Rosenthal 2000). Experimental exposure of swordtails to tetras in seminatural enclosures results in loss of swords in approximately $50 \%$ of males. In addition, tetras are highly aggressive and may injure swordtails in the course of agonistic interactions (Rosenthal 2000). Tetras are therefore likely to be an important agent of natural selection on visual traits in swordtails.

We examined the body size preference of A. mexicanus from a population sympatric with swordtails. We subsequently examined the sword preference of $A$. mexicanus from two populations: one sympatric with swordtails and one unlikely to have encountered swordtails in its evolutionary history.

\section{Methods}

We performed experiments assaying the preferences of Mexican tetras for male swordtail morphology using the following general procedure. Male Xiphophorus multilineatus were collected from the Río Coy, Río Pánuco drainage, San Luis Potosí, Mexico. Animals were maintained on a $14 \mathrm{~L}: 10 \mathrm{D}$ light cycle and fed TetraMin flake food daily. Tetras were deprived of food for $24 \mathrm{~h}$ prior to testing. Visual preferences were assayed using methods similar to those used for measuring female association in swordtails (Ryan and Wagner 1987; Ryan et al. 1990; Baer et al. 1995). We used a $60 \times 30-\mathrm{cm}$ aquarium filled to a depth of 20 $\mathrm{cm}$ and divided along its length by glass dividers into two flanking sections $15 \mathrm{~cm}$ wide and a central section $30 \mathrm{~cm}$ wide. Animals were allowed to acclimatize for $15 \mathrm{~min}$ prior 
Table 1: Xiphophorus multilineatus males used in preference experiments

\begin{tabular}{|c|c|c|c|}
\hline Stimulus fish & Standard length (mm) & $\begin{array}{l}\text { Sword extension } \\
\text { length }(\mathrm{mm})\end{array}$ & $\begin{array}{l}\text { Number of } \\
\text { stimulus fish }\end{array}$ \\
\hline \multicolumn{4}{|c|}{$\begin{array}{l}\text { Conspecific versus heterospecific-Nacimiento Río Hui- } \\
\text { chihuayán and Waller Creek Astyanax mexicanus: }\end{array}$} \\
\hline X. multilineatus & $34.6 \pm 4.1$ & $10.5 \pm 7.1$ & 5 \\
\hline A. mexicanus & $40.4 \pm 12.1$ & & 12 \\
\hline \multicolumn{4}{|c|}{$\begin{array}{l}\text { Body size morph preference-Río Choy A. mexicanus } \\
\text { (sympatric): }\end{array}$} \\
\hline Large & $32.5 \pm 2.4$ & $3.5 \pm 2.4$ & 12 \\
\hline Intermediate & $29.3 \pm 1.4$ & $3.8 \pm 2.0$ & 10 \\
\hline Small & $23.2 \pm 1.3$ & $1.6 \pm 1.2$ & 10 \\
\hline \multicolumn{4}{|c|}{$\begin{array}{l}\text { Sword preference-Nacimiento Río Huichihuayán } A \text {. } \\
\text { mexicanus (sympatric): }\end{array}$} \\
\hline Sword & $32.2 \pm 2.7$ & $5.1 \pm 3.4$ & 5 \\
\hline No sword & $32.1 \pm 1.8$ & 0 & 5 \\
\hline \multicolumn{4}{|c|}{ Sword preference-Waller Creek A. mexicanus (allopatric): } \\
\hline Sword & $37.0 \pm 2.7$ & $14.9 \pm 3.2$ & 10 \\
\hline No sword & $37.2 \pm 2.5$ & 0 & 10 \\
\hline
\end{tabular}

to testing, with opaque sheets of Plexiglas covering the dividers and thus removing visual cues for both stimuli and subjects. An individual tetra was placed in the center section, and the swordtails were used as stimuli in the flanking sections. These dividers were then lifted, and the orientation of Astyanax mexicanus (left or right) was recorded for 3 min using a computer event-recording program. Orientation was operationally defined as the heading of the tetra's snout; a heading within the $90^{\circ}$ arc centered along the aquarium's lengthwise axis was scored as a preference, while a heading in the $90^{\circ}$ arc toward or away from the observer was recorded as neutral. Pilot tests showed that tetras spent the majority of the time in the central section, leaving it only for rapid attacks directed at the stimulus males. Tetras also habituated to the stimuli after $5 \mathrm{~min}$, making it unfeasible to use attack rate as a response measure. We therefore used orientation toward a stimulus as our measure of preference. After this 3-min period, the stimulus fish were switched to control for side biases, after which we repeated the acclimatization and testing periods. We alternated the side of first presentation, such that the larger, or sworded, male was initially on the left side in every other trial. Although male $X$. multilineatus used as stimulus exemplars were reused within experiments (see below), we used a new set of both stimulus exemplars and subject A. mexicanus for each experiment.

\section{Experiment 1}

We sought to test whether tetras' preferences for certain swordtail phenotypes reflected assessment in the context of predation or a more general shoaling response. We presented six tetras from Waller Creek and six tetras from the Río Huichihuayán with a choice between a sworded $X$. multilineatus and an A. mexicanus from the same population, approximately matched for total length. We used a new A. mexicanus as a stimulus in each trial; three male $X$. multilineatus were used in two trials each, and two were used in three trials (table 1). Data from the two populations were pooled for statistical analyses.

\section{Experiment 2}

We tested tetras to determine whether they exhibited the same preferences for body size classes as female swordtails. Astyanax mexicanus were collected from the Río Choy, Río Pánuco drainage, San Luis Potosí, Mexico, where they are sympatric with Xiphophorus nigrensis, the sister species of X. multilineatus (Rauchenberger et al. 1990), which exhibits a body size polymorphism (Ryan and Causey 1989) and sword and body shape characteristics similar to $X$. multilineatus. Prior to the start of testing, male $X$. multilineatus were sorted by body size class (Zimmerer and Kallman 1989) into separate aquaria. For each tetra tested, we used a trio of $X$. multilineatus males from each phenotypic size class: small $(<26 \mathrm{~mm})$, intermediate (26-31 $\mathrm{mm})$, and large $(>31 \mathrm{~mm})$. Each individual male was thus used in two tests with the same female; for example, the same large male was used in both the large-versus-small comparison and in the large-versus-intermediate comparison. Large and intermediate males tend to have longer swords than small males in nature; the large and inter- 
mediate males in our sample had significantly longer swords than the small males (table 1; Mann-Whitney $U=49, P<.01)$. We tested three pairwise preferences: large versus small, large versus intermediate, and intermediate versus small. Because of permit restrictions, we were unable to use a distinct stimulus swordtail for each tetra. We used a total of 12 large males and 10 each of small and intermediate males. Xiphophorus multilineatus males were each used in sets of trials for two different females; four intermediate and three small males were used in trials for three subjects (table 1). To control for order effects, we systematically rotated the order of presentation of the three body size class comparisons. After testing, we measured the standard length (snout to hypural plate) and sword extension length (distance from the intersection of a line perpendicular to the axis of the ventral-most unextended caudal ray and crossing its tip with the ventral margin of the caudal fin to the tip of the longest caudal ray) of each male. Morphometrics for each stimulus class are given in table 1. All statistical tests were two tailed.

\section{Experiment 3}

We tested tetra preferences for male swords, first with a population sympatric with swordtails and then with an allopatric population that had not encountered swordtails in its recent evolutionary history. The sympatric population was from the Nacimiento of the Río Huichihuayán, Río Pánuco drainage, San Luis Potosí, where A. mexicanus co-occurs with the swordtails Xiphophorus cortezi and Xiphophorus pygmaeus; the latter has secondarily lost the sword. The allopatric population was the result of introductions of A. mexicanus from the Rio Grande drainage, Texas (Birkhead 1980). Neither the Colorado River nor Rio Grande drainages contain Xiphophorus.

We selected pairs of large $X$. multilineatus that were closely matched for body size and clipped off the sword extension (Basolo 1995a) of one individual. Fin clipping is a standard method of identifying fish or obtaining tissue samples from live individuals and is considered "a recommended procedure for many studies" (American Society of Ichthyologists and Herpetologists 1988). To control for any effects of manipulation, we clipped the sword of the sworded male $0.5-1 \mathrm{~mm}$ from the distal end of the sword. This procedure provided a control for any effects of manipulating the sword on male behavior. Since only a limited subset of $X$. multilineatus could be closely matched for body size, we reused $X$. multilineatus across treatments (table 1). We conducted two sets of tests: one on A. mexicanus from the Nacimiento Río Huichihuayán population, followed by tests on the Waller Creek population. We used a different set of male X. multilineatus for tests on each population. For the Waller Creek A. mexi- canus, each male $X$. multilineatus stimulus pair was used for two different subjects (10 stimulus pairs total). For the tests on the Nacimiento Río Huichihuayán population, three male pairs were used twice, and two were used three times (table 1). We used two-tailed statistical tests for the first set of trials. Since the results of the first set of trials gave us a clear a priori prediction, statistical tests on the second set of trials were one tailed.

\section{Results}

Tetras oriented significantly more to Xiphophorus multilineatus males than to similarly sized conspecifics (fig. 1; mean response to $X$. multilineatus, $137 \pm 16 \mathrm{~s}$ [mean \pm $\mathrm{SE}]$; mean response to Astyanax mexicanus, $82 \pm 15 \mathrm{~s}$; Wilcoxon signed-ranks test, $N=12, Z=-2.04, P<$ $.05)$. Tetras significantly preferred large to small $X$. multilineatus males (fig. $2 A$; Wilcoxon signed-ranks test, $N=23, Z=-3.06, P<.002)$ and intermediate to small males (fig. $2 B ; N=23, Z=-2.77, P<.01$ ) but did not show a preference between large and intermediate males (fig. $2 C ; N=24, Z=-0.06, P=.95$ ). Tetras in both the sympatric and allopatric populations significantly preferred the males with swords over their size-matched, manipulated, swordless counterparts (Nacimiento Río Huichihuayán, fig. 3A: $N=12, Z=-2.20, P<.02$; Waller Creek, fig. $3 B: N=20, Z=-1.76, P<.05)$. There was no significant difference in response between populations (Mann-Whitney $U$-test statistic $=123, N=32, \quad P=$ $.91)$.

\section{Discussion}

The visual preferences of Mexican tetras for male swordtail traits are markedly similar to the preferences of females. While these preferences do not necessarily predict the probability of attack, they do indicate the extent to which

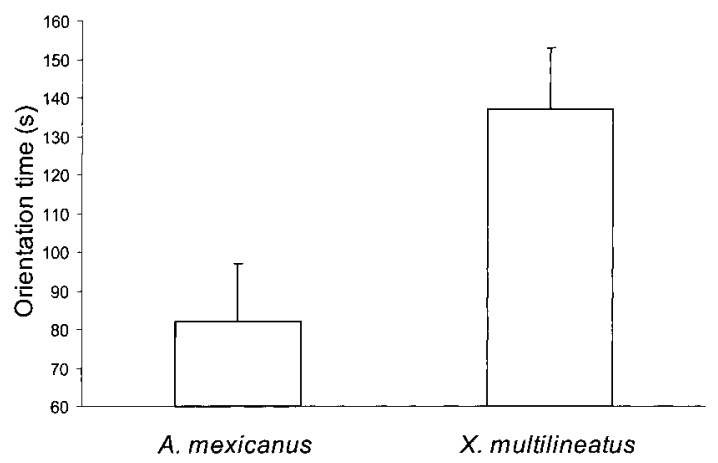

Figure 1: Orientation time ( $s$; mean $\pm \mathrm{SE}$ ) of Astyanax mexicanus with conspecific males versus Xiphophorus multilineatus males. 
Xiphophorus females

A. mexicanus

large vs. small

A
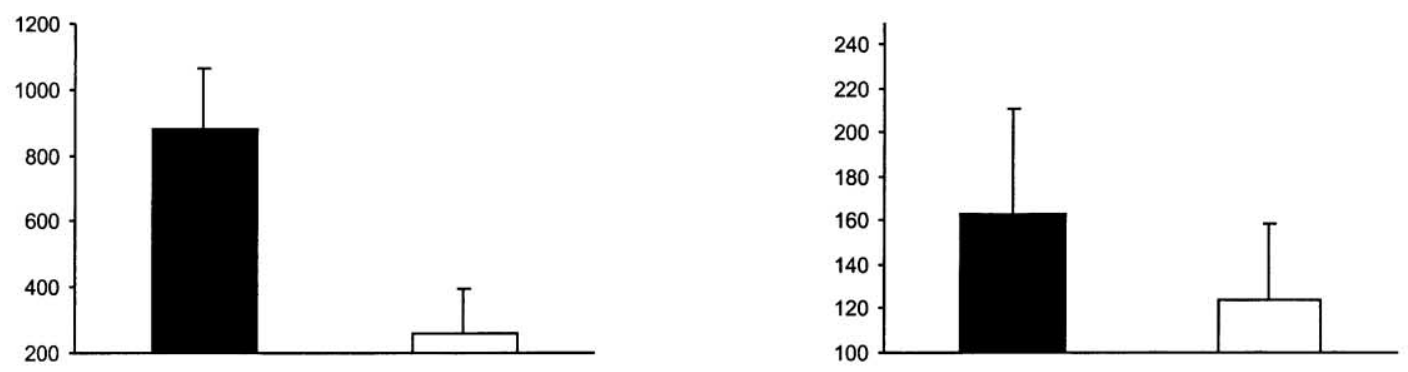

small vs. intermediate

B
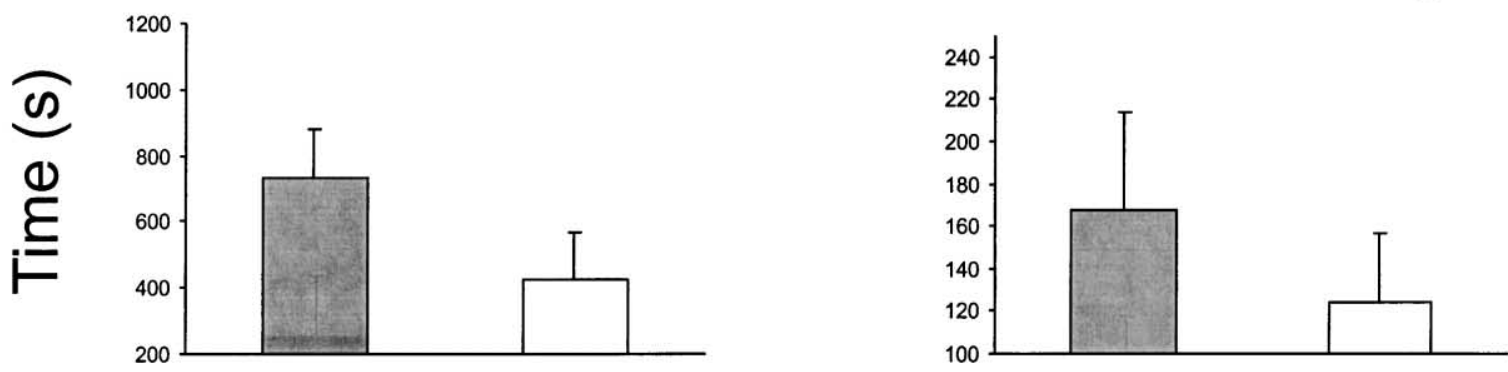

large vs. intermediate
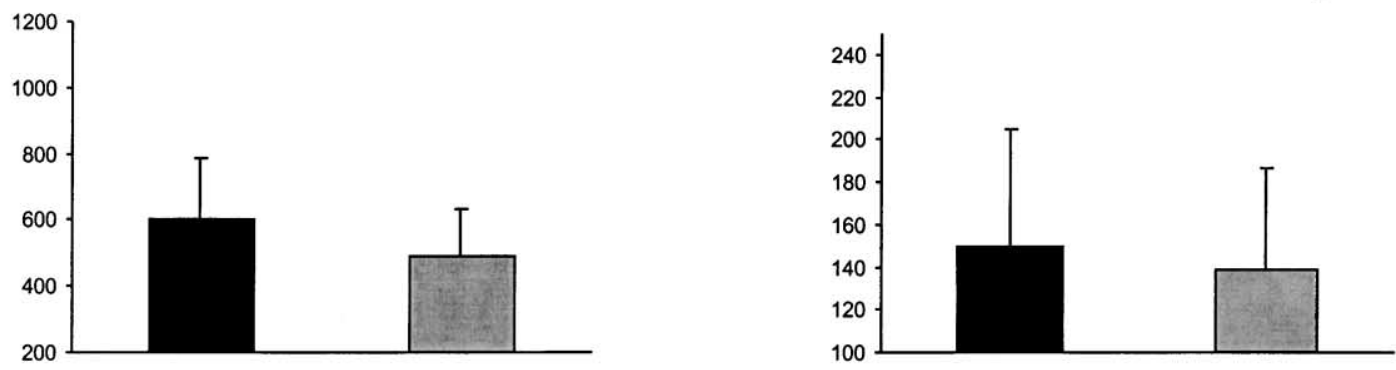

large

intermediate

small

Figure 2: Association time ( $s$; mean \pm SE) of female Xiphophorus nigrensis with conspecific males (after Ryan et al. 1990) and orientation time (s) of Astyanax mexicanus to Xiphophorus multilineatus males. Each row shows responses of female swordtails and tetras to the same male swordtail pairs: $(A)$ large versus small, $(B)$ intermediate versus small, and $(C)$ large versus intermediate. 

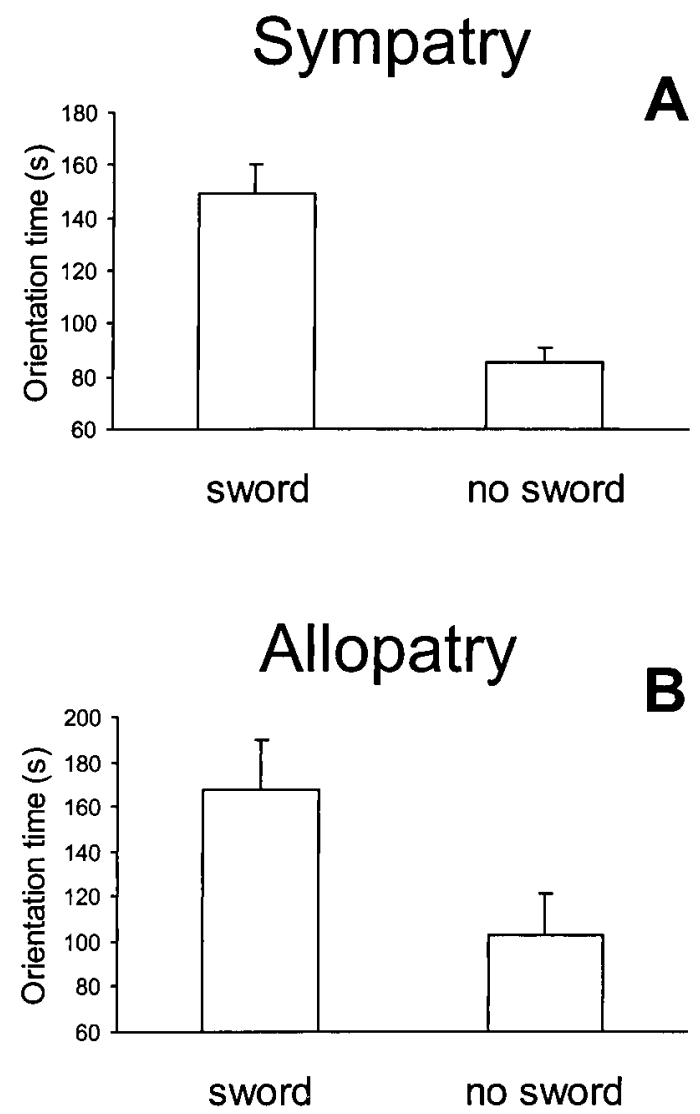

Figure 3: Orientation time ( $s$; mean $\pm \mathrm{SE}$ ) to Xiphophorus multilineatus males of Astyanax mexicanus from $(A)$ the Nacimiento of the Río Huichihuayán, Río Pánuco system, and (B) Waller Creek, Colorado River system.

predators detect and attend to different phenotypes, a necessary first step in a predator-prey encounter (Endler 1991a). The significant preference of tetras for swordtails over similarly sized conspecifics, moreover, indicates that the preference is more specific than an inclination to shoal with other fishes and is likely to reflect a predation-specific response.

Ryan et al. (1990) suggested that females were attending primarily to the presence of courtship in intermediate and large males. Since males were not courting in this study, the predator preference is likely due to the greater aspect ratio and ornamentation of the large and intermediate males. The congruence of Astyanax mexicanus responses with those of female Xiphophorus suggests that predator preferences are influenced by factors other than gross size: large and intermediate males are similarly ornamented but differ in size, yet we were unable to detect a preference between the morphs. As with previous studies of preference for body size morphs (Ryan et al. 1990), we did not attempt to control for sword length in experiments presenting $A$. mexicanus with different $P$ genotypes, so this preference may in part be due to the fact that the intermediate and large males were, on average, expressing longer swords.

It is unclear whether predator preference plays a role in maintaining the genetic polymorphism in body size. Equal fitnesses of body size morphs can be explained by differences in maturation schedules and mating success alone, without assuming differences in postmaturation mortality (Ryan et al. 1992). While large males are more conspicuous to predators, they also have greater swimming endurance (Ryan 1988) and are likely to be faster swimmers. These factors may offset the conspicuousness cost of increased body size.

The presence or absence of a sword ornament elicited a preference from tetras in both populations. The need to size match stimulus males in these experiments limited the number of male exemplar pairs we could use, especially for the Río Huichihuayán population. Tetras exhibited consistent responses to all male stimulus pairs, however, which suggests that the effect of manipulating sword length was not obscured by random variation in other male traits. Tetras from the Río Huichihuayán are sympatric with Xiphophorus cortezi, which expresses a conspicuous sword, and Xiphophorus pygmaeus, in which the sword has been secondarily lost. Río Huichihuayán tetras exhibited preferences strikingly similar to those of allopatric A. mexicanus in the Rio Grande drainage, which have likely been separated from swordtail habitat by the Sierra Tamaulipas, and $>1,000 \mathrm{~km}$, since the Eocene (Rauchenberger et al. 1990). The substantial natural barriers between the Waller Creek population and A. mexicanus populations currently in sympatry with swordtails make it extremely unlikely that current gene flow is maintaining visual preferences in tetras. We cannot exclude the possibility that ancestors of the Waller Creek tetras may have occurred in sympatry with a swordtail ancestor and that the observed preference for swords is a vestige of a coevolutionary process. Nevertheless, the preference is quite ancient and has not been maintained due to selection for detecting swordtails. Astyanax mexicanus thus appear to share a preexisting bias for swords along with swordtails (Basolo 1990a), platyfishes (Basolo 1990b), and Priapella (the sister taxon of Xiphophorus; Basolo 1995b). Such a bias could reflect a broad, relatively low-level preference for large body size (Rosenthal and Evans 1998).

Patterns of sword expression across the northern swordtails are associated with predation risk; in populations with high densities of A. mexicanus, only the largest males express prominent swords (Rosenthal 2000). The conspicuousness of swords to predators may account for this pattern. Swords are metabolically inexpensive to produce 
compared with increased body size (Basolo 1998) and may have evolved as a less costly means of mimicking large apparent size (Rosenthal and Evans 1998). This advantage is offset by the increased predation cost of the sword (Rosenthal 2000).

Predation is also likely to have shaped the evolution of the sword as a visual signal. Evidence from other systems suggests that visual signals can evolve to minimize the risk of detection by predators while remaining conspicuous to conspecifics. The arthropod predators of guppies (Poecilia reticulata) and the poeciliid Phalloceros caudimaculatus are relatively insensitive to red, while some fish predators of guppies are insensitive to blue and ultraviolet (Endler 1982, 1991b). Males in $P$. reticulata (Endler 1991b) and $P$. caudimaculatus (Endler 1982) populations with arthropod predators have evolved red and orange markings, while guppy populations with fish predators have evolved blue and ultraviolet ornaments (Endler 1991b). This minimizes the contrast of the markings with background body color from a predator's point of view while maintaining contrast for conspecific receivers.

Comparative evidence suggests that the internal contrast of swords may respond to predation as well. The sword of a southern swordtail, Xiphophorus helleri, is characterized by a central stripe of orange yellow carotenoid pigments flanked by black melanin on the dorsal and ventral margins. Xiphophorus malinche, a northern swordtail in allopatry from A. mexicanus, expresses a similar sword. The swords of other northern swordtails, all in sympatry with A. mexicanus (Xiphophorus nigrensis, X. cortezi, Xiphophorus nezahualcoytl, Xiphophorus montezumae, and the Xiphophorus multilineatus used in this study), tend to lack colors conspicuous to the human eye. Ultraviolet imaging and spectroradiometry reveal that the swords of $X$. nigrensis reflect primarily in the ultraviolet. Astyanax mexicanus, like humans, lacks sensitivity in the ultraviolet; the color properties of the sword may thus have evolved to minimize conspicuousness to predators (G. G. Rosenthal, M. E. Cummings, and M. J. Ryan, unpublished data). Unlike body markings, however, swords are viewed against a variety of natural backgrounds. This limits the opportunity for privacy; even if internal contrast is minimized, the sword is likely to remain visible to predators as a dark object.

The Waller Creek population of tetras has no current experience and no recent evolutionary contact with swordtails. The sword is thus a novel, relatively conspicuous feature of the tetras' prey regime. Theory makes diametrically opposed predictions about how predators should respond to novel, conspicuous prey. By definition, more conspicuous prey are more likely to be detected, which could increase predation rate (Curio 1976; O'Brien et al. 1976). Alternatively, novel phenotypes may be at lower risk of predation. Predators may avoid unfamiliar prey items that may be associated with aposematic or aversive stimuli (Götmark and Olsson 1997). Predation may be apostatic, with prey phenotypes at high frequencies taken disproportionately more often (Allen and Clarke 1968). Götmark (1994) found that stuffed blackbirds (Turdus merula) bearing novel red wing patches were less likely to be attacked than unornamented males.

If the visual preferences demonstrated here are an indication of predation risk, sworded males should suffer higher predation rates than nonsworded males, even at low frequencies. Aposematism generally takes the form of bright, high-contrast color patterns (Bradbury and Vehrencamp 1998) rather than morphological ornamentation, which may explain the apparent lack of hesitation in $A$. mexicanus vis-à-vis these novel prey.

Astyanax mexicanus lack fin elongation or other morphological ornamentation, so it is unlikely that sexual selection within tetras is maintaining their visual biases. Rather, the preferences of $A$. mexicanus for swords and body size reflect the broad nature of the conspicuousness of these traits. Given an appropriate background and viewing distance, an increase in sword length or body size will result in an increased probability of detection by a receiver. Other ornaments that have evolved in response to preexisting biases, such as chucks in túngara frogs (Ryan and Rand 1993) and feather ornaments in auklets (Jones and Hunter 1998), are similarly broadcasting signals that are likely to be readily detectable to a wide array of receivers. Such signals may therefore carry a built-in cost of increased conspicuousness to eavesdroppers such as predators.

Darwin ([1871] 1936) attributed the attraction of conspicuous traits for female animals to an "aesthetic sense" shared with humans. Recent work has refined this aesthetic in terms of emergent biases for complex or exaggerated stimuli (Ryan 1990; Enquist and Arak 1993; Burley and Symanski 1998) or widespread directional biases in mating preferences (Ryan and Keddy-Hector 1992). Darwin ([1871] 1936, p. 467) postulated that "the taste for the beautiful is confined ... to the attractions of the opposite sex." Our results suggest that this is not the case. Latent aesthetics can be widely shared and expressed in a variety of contexts, and, at least in the case of $A$. mexicanus, the term "taste" need not be metaphorical.

\section{Acknowledgments}

We thank E. Atarod, J. Bosch, C. Elmore, R. Engeszer, C. Gabor, M. Rosenthal, H. Rosenthal, and especially M. Stephens for assistance in the field. A. Alexander, J. Crutchfield, L. Gilbert, and the Brackenridge Field Laboratory provided facilities for housing study animals. J. Endler, J. Wiens, and two anonymous reviewers provided valuable comments on 
drafts of this article. We are grateful to the government of Mexico, Secretaría de Medio Ambiente, Recursos Naturales y Pesca for Permiso de Fomento 041099-213-03 granted to F.J.G.L. and to the Consejo del Sistema Nacional de Educación Tecnológica for a scholarship (97147AI) in the Programa de Integración de Alumnos a la Investigación y Desarrollo Tecnológico awarded to T.Y.F.M. This work was funded by National Science Foundation grants IBN 9630230 to M.J.R. and 97-01008 to G.G.R. and M.J.R.

\section{Literature Cited}

Allen, J. A., and B. Clarke. 1968. Evidence for apostatic selection by wild passerines. Nature (London) 220: 501-502.

American Society of Ichthyologists and Herpetologists. 1988. Guidelines for use of fishes in field research. Fisheries 13:16-23.

Andersson, M. 1994. Sexual selection. Princeton University Press, Princeton, N.J.

Baer, C. F., M. Dantzker, and M. J. Ryan. 1995. A test for preference of association on a color polymorphic poeciliid fish: laboratory study. Environmental Biology of Fishes 43:207-212.

Basolo, A. L. 1990a. Female preference for male sword length in the green swordtail (Pisces: Poeciliidae). Animal Behaviour 40:332-338.

-1990b. Female preference predates the evolution of the sword in swordtail fish. Science (Washington, D.C.) $250: 808-810$.

- 1995a. A further examination of a preexisting bias favoring a sword in the genus Xiphophorus. Animal Behaviour 50:365-375.

— 1995b. Phylogenetic evidence for the role of a preexisting bias in sexual selection. Proceedings of the Royal Society of London B, Biological Sciences 259: 307-311.

- 1998. Shift in investment between sexuallyselected traits: tarnishing of the silver spoon. Animal Behaviour 55:665-671.

Birkhead, W. S. 1980. Astyanax mexicanus (Filippi), Mexican tetra. Page 139 in D. S. Lee, C. R. Gilbert, C. H. Hocutt, R. E. Jenkins, D. E. McAllister, and J. R. Stauffer, Jr., eds. Atlas of North American freshwater fishes. North Carolina State Museum of Natural History, Raleigh.

Bradbury, J. W., and S. L. Vehrencamp. 1998. Principles of animal communication. Sinauer, Sunderland, Mass.

Burley, N. T., and R. Symanski. 1998. "A taste for the beautiful": latent aesthetic mate preferences for white crests in two species of Australian grassfinches. American Naturalist 152:792-801.

Curio, E. 1976. The ethology of predation. Springer, Berlin. Darwin, C. (1871) 1936. The origins of species by means of natural selection or the preservation of favored races in the struggle for life and the descent of man and selection in relation to sex. Random House, Modern Library, New York. Original edition, J. Murray, London. Endler, J. A. 1978. A predator's view of animal color patterns. Evolutionary Biology 11:319-364.

- 1980. Natural selection on color patterns in Poecilia reticulata. Evolution 34:76-91.

- 1982. Convergent and divergent effects of natural selection on color patterns in two fish faunas. Evolution $36: 178-188$.

1983. Natural and sexual selection on color patterns in poeciliid fishes. Environmental Biology of Fishes 9:173-190.

- 1991a. Interactions between predators and prey. Pages 169-201 in J. R. Krebs and N. B. Davies, eds. Behavioural ecology: an evolutionary approach. Blackwell Scientific, London.

- 1991b. Variation in the appearance of guppy color patterns to guppies and their predators under different visual conditions. Vision Research 31:587-608.

- 1992. Signals, signal conditions, and the direction of evolution. American Naturalist 139(suppl.): S125-S153.

Enquist, M., and A. Arak. 1993. Selection of exaggerated male traits by female aesthetic senses. Nature (London) 361:446-448.

Götmark, F. 1994. Does a novel bright colour patch increase or decrease predation? red wings reduce predation risk in European blackbirds. Proceedings of the Royal Society of London B, Biological Sciences 256: 83-87.

Götmark, F., and J. Olsson. 1997. Artificial colour mutation: do red-painted great tits experience increased or decreased predation? Animal Behaviour 53:83-91.

Haas, R. 1976. Sexual selection in Nothobranchius guentheri (Pisces: Cyprinodontidae). Evolution 30:614-622.

Jones, I. L., and F. M. Hunter. 1998. Heterospecific mating preferences for a feather ornament in least auklets. Behavioral Ecology 9:187-192.

Miller, R. R., and M. L. Smith. 1986. Origin and geography of the fishes of central Mexico. Pages 487-517 in C. H. Hocutt and E. O. Wiley, eds. The zoogeography of North American freshwater fishes. Wiley, New York.

Moodie, G. E. E. 1972. Predation, natural selection, and adaptation in an unusual threespine stickleback. Heredity 28:155-167.

O’Brien, W. J., N. A. Slade, and G. L. Vinyard. 1976. Apparent size as the determinant of prey selection by bluegill sunfish (Lepomis macrochirus). Ecology 57: 1304-1310.

Proctor, H. C. 1991. Courtship in the water mite Neumania 
papillator: males capitalize on female adaptations for predation. Animal Behaviour 42:589-598.

Rauchenberger, M., K. D. Kallman, and D. C. Morizot. 1990. Monophyly and geography of the Río Pánuco basin swordtails (genus Xiphophorus) with descriptions of four new species. American Museum Novitates 2975: $1-41$.

Rosenthal, G. G. 2000. The behavioral ecology of visual signaling in swordtails. Ph.D. diss. University of Texas, Austin.

Rosenthal, G. G., and C. S. Evans. 1998. Female preference for swords in Xiphophorus helleri reflects a bias for large apparent size. Proceedings of the National Academy of Sciences of the USA 95:4431-4436.

Rowland, W. J. 1989. The ethological basis of mate choice in male threespine sticklebacks, Gasterosteus aculeatus. Animal Behaviour 38:112-120.

Ryan, M. J. 1988. Phenotype, genotype, swimming endurance, and sexual selection in a swordtail (Xiphophorus nigrensis). Copeia 1988:484-487.

- 1990. Sensory systems, sexual selection, and sensory exploitation. Oxford Surveys in Evolutionary Biology 7:157-195.

- 1998. Sexual selection, receiver biases, and the evolution of sex differences. Science (Washington, D.C.) 281:1999-2003.

Ryan, M. J., and B. A. Causey. 1989. "Alternative" mating behavior in the swordtails Xiphophorus nigrensis and Xiphophorus pygmaeus (Pisces: Poeciliidae). Behavioral Ecology and Sociobiology 24:341-348.

Ryan, M. J., and A. Keddy-Hector. 1992. Directional patterns of female mate choice and the role of sensory biases. American Naturalist 139(suppl.):S4-S35.

Ryan, M. J., and A. S. Rand. 1993. Sexual selection and signal evolution: the ghost of biases past. Philosophical Transactions of the Royal Society of London B, Biological Sciences 340:187-195.
Ryan, M. J., and W. E. Wagner, Jr. 1987. Asymmetries in mating preferences between species: female swordtails prefer heterospecific males. Science (Washington, D.C.) 236:595-597.

Ryan, M. J., D. K. Hews, and W. E. Wagner, Jr. 1990. Sexual selection on alleles that determine body size in the swordtail Xiphophorus nigrensis. Behavioral Ecology and Sociobiology 26:231-237.

Ryan, M. J., C. M. Pease, and M. R. Morris. 1992. A genetic polymorphism in the swordtail Xiphophorus nigrensis: testing the prediction of equal fitnesses. American Naturalist 139:21-31.

Slagsvold, T., S. Dale, and A. Kruszewicz. 1995. Predation favours cryptic coloration in breeding male pied flycatchers. Animal Behaviour 50:1109-1121.

Staddon, J. E. R. 1975. A note on the evolutionary significance of "supernormal" stimuli. American Naturalist 109:541-545.

Tuttle, M. D., and M. J. Ryan. 1981. Bat predation and the evolution of frog vocalizations in the Neotropics. Science (Washington, D.C.) 214:677-678.

Wagner, W. E., Jr. 1996. Convergent song preferences between female field crickets and acoustically orienting parasitoid flies. Behavioral Ecology 7:279-285.

Wilbur, H. M. 1988. Interactions between growing predators and growing prey. Pages 157-172 in B. Ebenman and L. Persson, eds. Size-structured populations: ecology and evolution. Springer, Berlin.

Zimmerer, E. J., and K. D. Kallman. 1989. Genetic basis for alternative reproductive tactics in the pygmy swordtail, Xiphophorus nigrensis. Evolution 43:1298-1307.

Zuk, M., and G. R. Kolluru. 1998. Exploitation of sexual signals by predators and parasitoids. Quarterly Review of Biology 73:415-438. 